\title{
MODEL PEMBELAJARAN PROBLEM BASED LEARNING DENGAN STRATEGI SNOWBALL THROWING UNTUK MENINGKATKAN PRESTASI BELAJAR IPA SISWA
}

\author{
Ni Ketut Sukerni \\ SMP Negeri 3 Banjarangkan \\ Email: Ketut1968@gmail.com
}

\begin{abstract}
ABSTRAK
Penelitian ini bertujuan untuk meningkatkan prestasi belajar siswa dengan cara menerapkan model pembelajaran Problem Based Learning dengan metode Snowball Thowing dalam proses pembelajaran. Subjek penelitianny aadalah kelas VII B SMP Negeri 3 Banjarangkan tahun pelajaran 2018/2019. Data yang dikumpulkana dalah data kuantitatif berupa hasil belajar yang dikumpulkan menggunakan instrumentes. Hasil yang diperoleh di analisis dengan analisis deskriptif. Setelah berakhir melakukan analisis data diketahui bahwa peningkatan prestasi belajar sudah dapat diupayakan. Hal tersebut terbukti dari kenaikan nilai siswa dari rata-rata awal 60,33 dengan ketuntasan belajar 30\% pada siklus I meningkat menjadi 69,87 dengan ketuntasan belajar 0\% dan pada siklus II sudah meningkat menjadi 82,10 dengan ketuntasan belajar100\%. Data tersebut menuntut peneliti untuk membuat simpulan bahwa penerapan model pembelajaran Problem Based Learning dengan metode Snowball Thowing mampu meningkatkan prestasi belajar IPA siswa di kelasVII Bsemester I tahun pelajaran 2018/2019 di SMP Negeri 3 Banjarangkan.
\end{abstract}

Kata kunci: Problem Based Learning, Snowball Throwing, Prestasi Belajar

\section{ABSTRACT}

This study aims to improve student achievement by applying the Problem Based Learning learning model with the Snowball Thowing method in the learning process. The subject of the research was class VII B of SMP Negeri 3 Banjarangkan in the 2018/2019 school year. The data collected is quantitative data in the form of learning outcomes collected using test instruments. The results obtained were analyzed with descriptive analysis. After ending the data analysis it is known that an increase in learning achievement can already be pursued. This is evident from the increase in student scores from an initial average of 60,33 with 30\% mastery learning in the first cycle increased to 69,87 with 70\% mastery learning and in the second cycle has increased to 82,10 with $100 \%$ mastery learning. The data requires researchers to make the conclusion that the application of the Problem Based Learning model with the Snowball Thowing method is able to improve the learning achievement of science students in class VII B semester I of the 2018/2019 academic year at SMP Negeri 3 Banjarangkan.

Keywords: Problem Based Learning, Snowball Throwing, Learning Achievement

\section{PENDAHULUAN}

$\begin{array}{lrr}\text { Belajar bermakna adalah belajar } \\ \text { yang tidak sewenang-wenang, tidak } \\ \text { verbalistik akan tetapi merupakan } \\ \text { penggabungan } & \text { substansi } & \text { antara }\end{array}$

pengetahuan baru dalam struktur kognitif. Belajar bermakna juga merupakan upaya yang disengaja untuk menghubungkan pengetahuan baru dengan konsep yang lebih tinggi dalam struktur kognitif. Belajar 
JurnalSantiaji Pendidikan, Volume 10, Nomor2, Juli 2020 ISSN 2087-9016, e-ISSN 2685-4694

menghubungkan pengalaman dengan peristiwa atau benda dan merupakan komitmen tingkah laku siswa untuk menghubungkan pengetahuan baru dengan hasil belajar sebelumnya.

Untuk dapat menghubungkan struktur kognitif siswa, seorang guru harus mampu untuk menciptakan suasana yang menyebabkan siswa termotivasi aktif dan kreatif selama proses pembelajaran berlangsung dan harus difasilitasi secara terbimbing oleh guru dalam rangka memperoleh pemahaman kebermaknaan pengetahuan baru yang diperoleh. Namun selalu saja ada kendala dari setiap aktivitas yang melibatkan berbagai unsur dan komponen. Seperti juga yang dialami guru dalam kegiatan proses pembelajaran di kelas VII Bsemester I tahunpelajaran 2018/2019 di SMP Negeri 3 Banjarangkan.

Hambatan-hambatan yang terjadi di lapangan antara lain adalah kelas selalu pasif akibat pembelajaran yang monoton, kurang memanfaatkan strategi pembelajaran yang tepat dalam pembelajaran, tidak menggunakan modelmodel yang rekomentasikan para ahli pendidikan, tidak pernah mau merubah paradigma pendidikan dari pengajaran menjadi pembelajaran, sehingga proses pembelajaran hanya berjalan untuk mencapai target penguasaan materi saja.

Akibat suasana pembelajaran yang tidak terencana dengan baik, berdasarkan hasil observasi guru selaku peneliti yang mengajar di SMP Negeri 3 Banjarangkan terhadap siswa kelas VII B, rata-rata nilai yang diperoleh siswa baru 60,33 rata-rata tersebut masih jauh di bawah KKM mata pelajaran IPA di sekolah ini yaitu 70,00. Dari kegiatan yang dilakukan terdapat beberapa permasalahan yang segera harus ditangani. Permasalahan tersebut di antaranya rendahnya kesiapan siswa untuk mengikuti pelajaran, ini terlihat dari anak kurang aktif mengikuti kegiatan belajar mengajar pada awal proses pembelajaran. Siswa yang kemampuannya kurang, terlihat belum siap belajar yang ditandai siswa tersebut sedikit malas untuk mengerjakan apa yang diperintahkan oleh guru. Siswa tidak mempunyai motivasi dalam mengikuti proses pembelajaran.

Seorang guru harus mampu menerapkan suatu metode yang dapat memberikan solusi terhadap permasalahan yang ada di kelas. Metode merupakan cara untuk dapat melakukan sesuatu yang lebih baik. Seorang guru harus pandai memilih metode yang sesuai dengan pokok bahasan yang akan disampaikan. Apabila guru mampu memilih dan menerapkan metode ajar dengan baik, maka sudah dapat dipastikan hasil belajar siswa akan mampu ditingkat.

Salah satu metode yang tepat dalam menunjang pencapaian tingkat prestasi siswa yang lebih baik adalah penerapan model pembelajaran problem based learning dengan metode snowball throwing. Model ini dianggapefektif karena berpenekanan pada keaktifan siswa dalam memecahkan permasalahan yang telah dipersiapkan dengan terencana oleh guru, yang dalam pelaksanaannya akan mampu meningkatkan kualitas pembelajaran di sekolah.

Penelitimencobamenyampaikanrumu sanmasalah yang tepatmengacu pada latarbelakangmasalah yang telahdisampaikan.

Dalamhalinirumusanmasalah yang diajukanadalah: Apakahmodel pembelajaranProblem Based LearningdenganStrategi

SnowballThrowingdapatmeningkatkanprest asibelajarIPA siswakelasVII Bsemester I tahunpelajaran 2018/2019 di SMP Negeri3 
JurnalSantiaji Pendidikan, Volume 10, Nomor2, Juli 2020 ISSN 2087-9016, e-ISSN 2685-4694

Banjarangkan?Tujuanadalahsesuatuyang

merupakanhal yang

amatpentingdalamsebuahpenelitian.

Tanpaadatujuan yang jelas, penelitianitu bias sajatidaktentuarah. Oleh karenanyatujuanpenelitianinidirumuskanse bagaiberikut:

Untukmengetahuiseberapatinggipeningkata nprestasibelajarIPA siswakelas VII B semester I tahunpelajaran 2018/2019 setelahditerapkan model pembelajaranProblem Based

LearningdenganStrategi

SnowballThrowingdalampembelajaran.

Penelitianpendidikan

pada umumnyaditujukanuntukmemperolehlandas andalammempertimbangkansuatuprosedurk erja, khususnyaprosedurpembelajaran, menjamincarakerja yang efektif dan efisien, memperolehfakta-

faktatentangberbagaimasalahpendidikan,

dan menghindarkansesuatu yang dapatmerusak,

sertameningkatkankompetensi guru

dalammengembangkanpembelajaran.

Berdasarkanpemahamantersebut, secaraumumpenelitiantindakankelasberman faatuntuk: 1) Memperbaiki dan meningkatkankondisi-

kondisibelajarsertakualitaspembelajaran. 2) Meningkatkanlayanan professional dalamkontekspembelajaran,

khhususnyalayanankepadapesertadidiksehi nggaterciptalayanan prima.

Memberikesempatankepada guru berimprovisasidalammelakukantindakanpe mbelajaran yang direncanakansecaratepatwaktu dan sasarannya. 4) Memberikesempatankepada guru

mengadakankajiansecarabertahapkegiatanp embelajaran yang dilakukannyasehinggaterciptaperbaikan yang berkesinambungan. 5) Membiasakan guru mengembangkansikapilmiah, terbuka dan jujurdalampembelajaran.

Model pembelajaran merupakan kerangka konseptual yang melukiskan prosedur yang sistematis dalam mengorganisasi pengalaman belajar untuk mencapai tingkat belajar tertentu (Udin, 1997). Joyce, dkk. (2003)mengemukakan bahwa suatu model pembelajaran adalah suatu perencanaan atau pola yang digunakan sebagai pedoman pelaksanaan pembelajaran di kelas. Model pembelajaran merupakan suatu rencana atau pola yang digunakan untuk membentuk kurikulum, merancang bahan pengajaran dan membimbing pengajaran di kelas(Hamalik, 2011). Dari pendapat tersebut di atas dapat disimpulkan bahwa model pembelajaran merupakan kerangka konseptual dalam wujud suatu perencanaan pembelajaran yang melukiskan prosedur yang sistematis yang digunakan sebagai pedoman dalam pembelajaran di kelas.

Istilah model pembelajaran mempunyai empat ciri khusus yakni: 1) rasional teoretik yang logis yang disusun oleh para pencipta, 2) landasan pemikiran tentang apa dan bagaimana siswa belajar, 3) tingkah laku mengajar yang diperlukan agar model tersebut dapat berhasil, 4) lingkungan belajar yang diperlukan agar tujuan pembelajaran itu dapat tercapai (Sanjaya, 2006).

Sintaks suatu model pembelajaran menggambarkan keseluruhan urutan alur langkah yang pada umumnya diikuti oleh serangkaian kegiatan pembelajaran(Sudjana, 2009). Sintaks pembelajaran menunjukkan dengan jelas kegiatan-kegiatan apa yang perlu dilakukan oleh guru atau siswa dan tugas-tugas khusus yang dilakukan oleh siswa. Sintaks dari bermacam model pembelajaran mempunyai komponen yang sama seperti 
JurnalSantiaji Pendidikan, Volume 10, Nomor2, Juli 2020 ISSN 2087-9016, e-ISSN 2685-4694

diawali dengan menarik perhatian siswa dan memotivasi siswa agar terlibat dalam proses pembelajaran. Demikian pula setiap model pembelajaran selalu mempunyai tahap menutup pelajaran. Namun demikian ada perbedaan seperti perbedaan pengelolaan lingkungan belajar, perbedaan peran siswa, perbedaan peran guru, perbedaan ruang fisik dan perbedaan sistem sosial kelas. Perbedaan-perbedaan tersebut harus dipahami oleh para guru dalam menerapkan model pembelajaran agar dapat dilaksanakan dengan baik.

Model pembelajaran problem based learning (pembelajaran berbasis masalah), awalnya dirancang untuk program graduate bidang kesehatan oleh Barrows, (Barrows \& Tamblyn, 1980)yang kemudian diadaptasi dalam bidang pendidikan oleh Gallagher, (1995).Problem based learning disetting dalam bentuk pembelajaran yang diawali dengan sebuah masalah dengan menggunakan instruktur sebagai pelatihan metakognitif dan diakhiri dengan penyajian dan analisis kerja siswa.

Model pembelajaran problem based learning berlandaskan pada psikologi kognitif, sehingga fokus pengajaran tidak begitu banyak pada apa yang sedang dilakukan siswa, melainkan kepada apa yang sedang mereka pikirkan pada saat mereka melakukan kegiatan itu. Pada problem based learning peran guru lebih berperan sebagai pembimbing dan fasilitator sehingga siswa belajar berpikir dan memecahkan masalah mereka sendiri. Belajar berbasis masalah menemukan akar intelektualnya pada penelitian John Dewey (Ibrahim, 2000). Pedagogi Jhon Dewey menganjurkan guru untuk mendorong siswa terlibat dalam proyek atau tugas yang berorientasi masalah dan membentu mereka menyelidiki masalah-masalah tersebut. Pembelajaran yang berdayaguna atau berpusat pada masalah digerakkan oleh keinginan bawaan siswa untuk menyelidiki secara pribadi situasii yang bermakna merupakan hubungan problem based learning dengan psikologi Dewey. Selain Dewey, ahli psikologi Eropa Jean Piaget tokoh pengembang konsep konstruktivisme telah memberikan dukungannya. Pandangan konstruktivisme- kognitif yang didasari atas teori Piaget menyatakan bahwa siswa dalam segala usianya secara aktif terlibat dalam proses perolehan informasi dan membangun pengetahuannya sendiri (Ibrahim, 2000).

Tujuan pembelajaran dirancang untuk dapat merangsang dan melibatkan pebelajar dalam pola pemecahan masalah. Kondisi ini akan dapat mengembangkan keahlian belajar dalam bidangnya secara langsung dalam mengidentifikasi permasalahan. Dalam konteks belajar kognitif sejumlah tujuan yang terkait adalah belajar langsung dan mandiri, pengetahuan dan pemecahan masalah. Sehingga untuk mencapai keberhasilan, para pebelajar harus mengembangkan keahlian belajar dan mampu mengembangkan strategi dalam mengidentifikasi dan menemukan permasalahan belajar, evaluasi dan juga belajar dari berbagai sumber yang relevan.

Dalam hal ini ada dua hal yang harus terpenuhi. Pertama, harus dapat memunculkan konsep-konsep atau prinsipprinsip yang relevan dengan contentdomain yang dibahas. Kedua, permasalahan hendaknya riil sehingga memungkinkan terjadinya kesamaan pandang antarsiswa. Ada tiga alasan kenapa permasalahan harus nyata (realistik). (1) Siswa terkadang terbuka untuk meneliti semua dimensi dari permasalahan sehingga dapat mengalami kesulitan dalam menciptakan suatu permasalahan yang luas dengan informasi 
JurnalSantiaji Pendidikan, Volume 10, Nomor2, Juli 2020 ISSN 2087-9016, e-ISSN 2685-4694

yang sesuai. (2) Permasalahan nyata cenderung untuk lebih melibatkan siswa terhadap suatu konteks tentang kesamaan dengan permasalahan. (3) Siswa segera ingin tahu hasil akhir dari penyelesaian masalahnya.

Pebelajar dilibatkan dalam mempresentasikan permasalahan sehingga mereka merasa memiliki permasalahan tersebut. Ada dua hal pokok dalam mempresentasikan permasalahan. Pertama, jika siswa dilibatkan dalam pemecahan masalah yang autentik, maka mereka harus memiliki permasalahan tersebut. Kedua, adalah bahwa data yang ditampilkan dalam presentasi permasalahan tidak menyoroti faktor-faktor utama dalam masalah tersebut, namun dapat ditampilkan sebagai dasar pertanyaan sehingga tidak menampilkan informasi kunci.

Dalam hal ini peran guru sebagai fasilitator adalah mengembangkan kreativitas berpikir siswa dalam bentuk keahlian dalam pemecahan masalah dan membantu siswa untuk menjadi mandiri. Kemampuan dari tutor sebagai fasilitator keterampilan mengajar kelompok kecil dam proses pembelajaran merupakan penentu utama dari kualitas dan keberhasilan. Setiap metode pendidikan bertujuan:

Mengembangkan kreativitas pada siswa dan keahlian berpendapat. (2) Membantu mereka untuk menjadi mandiri. Sedangkan tutorial adalah suatu penggunaan keahlian yang menitikberatkan masalah dasar belajar langsung mandiri (Barrows dalam Savery \& Duffy, 1994).

Langkah-langkah yang perlu diperhatikan dalam merancang program pengajaran yang berorientasi pada problem based learning sehingga proses pembelajaran benar-benar berpusat pada siswa (student centered) adalah sebagai berikut (Gallagher \& Stepien, 1995): 1)
Fokuskan permasalahan (problem) sekitar pembelajaran konsep-konsep esensial yang strategis. Gunakan permasalahan dan konsep untuk membantu siswa melakukan investigasi substansi isi (content). 2) Berikan kesempatan kepada siswa untuk mengevaluasi gagasannya melalui eksperimen atau studi lapangan. Siswa akan menggali data-data yang diperlukan untuk memecahkan masalah yang dihadapinya. 3) Berikan kesempatan kepada siswa untuk mengelola data yang mereka miliki yang merupakan proses metakognisi. 4) Berikan kesempatan kepada siswa untuk mempresentasikan solusi-solusi yang mereka kemukakan. Penyajian dapat dilakukan dalam bentuk seminar atau publikasi atau dalam bentuk penyajian poster.

\begin{tabular}{llr}
\multicolumn{2}{c}{ Sebagai model pembelajaran } \\
problem based learning & disamping \\
memiliki keunggulan juga memiliki
\end{tabular} kelemahan. Sanjaya (2006) menyatakan keunggulan problem based learning adalah: 1) Pemecahan masalah merupakan teknik yang cukup bagus untuk lebih memahami isi pelajaran. 2) Pemecahan masalah dapat menantang kemampuan siswa serta memberikan kepuasan untuk menemukan pengetahuan baru bagi siswa. 3) Pemecahan masalah dapat meningkatkan aktivitas pembelajaran siswa. 4) Pemecahan masalah dapat membantu siswa bagaimana mentransfer pengetahuan untuk memahami masalah dalam kehidupan nyata. 5) Pemecahan masalah dapat membantu siswa untuk mengembangkan pengetahuan barunya dan bertanggung jawab dalam pembelajaran yang mereka lakukan. Disamping juga dapat mendorong untuk melakukan siendiri baik terhadap hasil maupun proses belajarnya. 6) Melalui pemecahan masalah bisa diperlihatkan bahwa setiap mata pelajaran pada dasarnya 
JurnalSantiaji Pendidikan, Volume 10, Nomor2, Juli 2020 ISSN 2087-9016, e-ISSN 2685-4694

merupakan cara berpikir dan sesuatu yang dimengerti oleh siswa bukan hanya sekedar belajar dari guru atau dari buku saja. 7) Pemecahan masalah dipandang lebih mengasikkan dan disukai siswa. 8) Pemecahan masalah dapat mengembangkan kemampuan siswa untuk berpikir kritis dan mengembangkan kemampuan mereka untuk menyesuaikan pengetahuan baru. 9) Pemecahan masalah dapat memberikan kesempatan kepada siswa untuk mengaplikasikan pengetahuan yang telah mereka miliki dalam dunia nyata. 10) Pemecahan masalah dapat mengembangkan minat siswa untuk secara terus-menerus belajar sekalipun belajar pada pendidikan formal telah berakhir.

Sedangkan kelemahannya adalah: 1) Manakala siswa tidak memiliki minat atau tidak memiliki kepercayaan sehingga masalah yang dipelajari sulit dipecahkan maka siswa akan merasa enggan untuk mencoba. 2) Keberhasilan pembelajaran ini membutuhkan cukup banyak waktu. 3) Tanpa pemahaman mengapa mereka berusaha memecahkan masalah yang sedang dipelajari, maka siswa tidak akan belajar apa yang mereka ingin pelajari.

Belajar berbasis masalah biasanya terdiri dari 5 tahap yang dimulai dengan (1) orientasi siswa kepada masalah, (2) mengorganisasikan siswa untuk belajar, (3) membimbing penyelidikan individual maupun kelompok, (4) mengembangkan dan menyajikan hasil karya dan (5) menganalisis dan mengevaluasi proses pemecahan masalah (Nur, 2000).

Snowball Throwing adalahparadigmapembelajaranefektif yang merupakanrekomendasi UNESCO, yakni: belajarmengetahui (learning to know), belajarbekerja (learning to do), belajarhidupbersama (learning to live together), dan belajarmenjadidirisendiri (learning to be) (Depdiknas, 2001).

$$
\text { Metodepembelajaran snowball }
$$

throwing adalahsuatumetodepembelajaran yang diawalidenganpembentukankelompok yang

diwakiliketuakelompokuntukmendapattuga sdari guru kemudianmasingmasingsiswamembuatpertanyaan yang dibentukseperti bola (kertaspertanyaan) laludilemparkesiswa lain yang masingmasingsiswamenjawabpertanyaandari bola yang diperoleh (Kisworo, dalamMukhtari, 2010).

Metode snowball-throwing
merupakan
salahsatumodifikasidariteknikbertanya
yangmenitikberatkan pada kemampuanmerumuskanmeningkatkanmoti vasisiswabertanyamelaluimetode snowballthrowingpertanyaan yang dikemasdalamsebuahpermainan yang menarikyaitusalingmelemparkan bola salju (snowball-throwing)

yangberisipertanyaankepadasesamateman.

Metodeyang

dikemasdalamsebuahpermainaninimembutu hkankemampuan yang sangatsederhana yang bisadilakukan oleh hampirsetiapsiswadalammengemukakanper tanyaansesuaidenganmateri yang dipelajarinya.Metode snowball throwing adalahmetodeyang

digunakanuntukmemperdalamsatutopik.Me todeinibiasadilakukan oleh beberapakelompok yang terdiridari lima sampaidelapanorang yang memilikikemampuanmerumuskanpertanyaa $\mathrm{n} \quad$ yang ditulisdalamsebuahkertasmenyerupai bola. Kemudian,

kertasitudilemparkankepadakelompok lain yang 
JurnalSantiaji Pendidikan, Volume 10, Nomor2, Juli 2020 ISSN 2087-9016, e-ISSN 2685-4694

untukditanggapidenganmenjawabpertanyaa

n yangdilemparkantersebut(Widodo, 2009).

\section{Langkah-langkah}

yang

ditempuhdalammetodeiniialah: 1) Guru menyampaikanmateri yang akandisajikan.

2) Guru membentukkelompok-kelompok dan memanggilmasingmasingketuakelompokuntukmemberikanpe njelasantentangmateri. 3) Masingmasingketuakelompokkembalikekelompok nyamasing-masing,

kemudianmenjelaskanmateri yang disampaikan oleh guru kepadatemannya. 4) Kemudianmasingmasingsiswadiberikansatulembarkerjauntuk menuliskan. 5) Pertanyaanapasaja yang menyangkutmateri yang sudahdijelaskan oleh ketuakelompok.

Kemudiankertastersebutdibuatseperti bola dan dilempardarisatusiswakesiswa yang lain selamakuranglebih 5 menit. 7) Setelah siswamendapatsatu

bola/satupertanyaandiberikankesempatanke padasiswauntukmenjawabpertanyaan yang tertulisdalamkertasberbentuk bola tersebutsecarabergantian. 8) Guru memberikankesimpulan. 9) Guru mengevaluasikegiatantersebutdengancaram emberikankomentarsekaligusmemberikanp enilaianmengenaijenis dan bobotpertanyaan, rumusankalimat, kemudianmemberikancontohrumusanpertan yaan yang benar. 10) Penutup.

Metode snowball-throwing inidapatmemberikankesempatankepadatem andalamkelompokuntukmerumuskanpertan yaansecarasistematis.

Di sampingitudapatmembangkitkankeberanian siswadalammengemukakanpertanyaandeng antuntunanpertanyaankepadateman lain maupun guru.Juga

melatihsiswamenjawabpertanyaan yangdiajukan oleh temannyadenganbaik. Dapatpula merangsangsiswamengemukakanpertanyaa nsesuaidengantopik yang sedangdibicarakandalampelajarantersebut. Berikutnyadapatmengurangi rasa takutsiswadalambertanyakepadatemanmaup un guru sertamelatihkesiapansiswa. Terakhir, denganmenggunakanmetodeinimemungkin kansiswasalingmemberikanpengetahuan.

Mukhtari, (2010), mengatakanbahwadalampendidikanadaemp atunsur yang memegangperananpenting dan salingberkaitansatusama lain yaitu: siswasebagaipelaku, guru sebagaipelaksana, sekolahsebagai media, dan orang tuasebagaipendukung. Pendidikan di sekolahmengarahkansiswasupayamemperol ehpengetahuan, pemahaman, ketrampilan, sikap dan nilai, yang semuanyamenunjangperkembangansiswa. MenurutSlameto

bahwabelajaradalahsuatu proses usaha yang dilakukanseseoranguntukmemperolehsuatu perubahantingkahlaku yang barusecarakeseluruhan, sebagaihasilpengalamannyasendiridalamint eraksidenganlingkungannya.

Secarasederhanadaripengertianbelajarsebag aimana yang dikemukakan oleh pendapat di atas,

dapatdiambilsuatupemahamantentanghakek atdariaktivitasbelajaradalahsuatuperubahan yang terjadidalamdiriindividu.

Gronlund(dalam Saifuddin, 1996) merumuskanbeberapaprinsipdasardalampen gukuranprestasiyaitusebagaiberikut : a) Tesprestasiharusmengukurhasilbelajar yang telahdibatasisecarajelassesuaidengantujuani ntruksional.

Tesprestasiharusmengukursuatusampel yang representatifdarihasilbelajar dan darimateri yang dicakup oleh program intruksionalataupengajaran. 
JurnalSantiaji Pendidikan, Volume 10, Nomor2, Juli 2020 ISSN 2087-9016, e-ISSN 2685-4694

Tesprestasiharusberisi

dengantipe yang paling cocokgunamengukurhasilbelajar yang

diinginkan.

Tesprestasiharusdirancangsedemikianrupa agar

sesuaidengantujuanpenggunaanhasilnya. e)

Reliabilitastesprestasiharusdiusahakansetin ggimungkin dan hasilukurnyaditafsirkandenganhati-hati. f) Tesprestasiharusdapatdigunakanuntukmeni ngkatkanbelajar para anakdidik.

Dengandemikianhasilbelajarsiswada patdiukurdengantigaranahyaituranahkogitif, afektif dan psikomotorik. Ketigaranahtersebutmenjadiobjekpenelitian hasilbelajar. Dari ketigaanahtersebut, ranahkognitiflah yang paling banyakdinilai oleh

guru disekolahkarenaberkaitandengankemampua nsiswadalammenguasaibahanpengajaran.

Berdasarkankutipan di atas, makadapatdiambilsuatupengertianbahwapre stasibelajarituidentikdenganpenggunaanmat eripelajaran.

Karena

hakikatdarinilaiperolehanbelajardiawalidari kemampuansiswauntukmenjawabsoal-soal yang diajukan guru secaratertulis. Dengandemikiantingkatpenguasaanmaterim asing-masingsiswa,

secaraotomatisakanmembedakanprestasibel ajarnya.

Menurut Gagne (dalamHasibuan, 2002), tujuanbelajaradalah:

Keterampilanintelektual yang merupakanhasilbelajarterpentingdarisisteml ingkunganskolastik. b) Strategikognitif, mengaturcarabelajar dan berpikirseseorangdidalamarti yang seluasluasnya, termasukkemampuanmemecahkanmasalah. c) Informasi verbal, pengetahuandalamartiinformasi dan fakta. d) Keterampilanmotorik yang diperoleh di sekolahantara lain keterampilanmenulis, mengetik, menggunakanjangkadll. Sikap dan

nilaiberhubungandenganarahsertaintensitas emosional yang dimilikiseseorangsebagaimanadapatdisimp ulkandarikecenderungantingkahlakuterhada p orang lain, barangataukejadian

Slameto (2010) berpendapatciriciriperubahantingkahlakusebagaihasilbelaja radalah: 1) Perubahansecarasadar; 2) Perubahanbersifatkontinyu dan fungsional; 3) Perubahanbersifatpositif dan aktif; 4) Perubahanbukanbersikapsementara; 5) Perubahanbertujuan dan terarah, serta 6) Perubahanmencakupseluruhaspektingkahla $\mathrm{ku}$.

Faktor-faktor yang menentukanpencapaianhasilbelajarantara lain: a) Faktor yang berasaldaridalamdirisiswa. Faktor yang berasaldaridalamdirisiswamisalnyakemamp uan yang dimilikinya, motivasibelajar, minat dan perhatian, sikap dan kebiasaanbelajar, ketekunan, sosialekonomi, faktorfisik dan psikis. b) Faktor yang berasaldariluardirisiswaataufaktorlingkunga n.Salah satulingkunganbelajar yang paling dominanmempengaruhihasilbelajar di sekolahadalahkualitaspengajaran, yaituefektiftidaknya proses belajarmengajardalammencapaitujuanpenga jaran(Sudjana, 2009).

Berdasarkanbeberapapendapat di atasdapatdisimpulkanbahwapencapaianhasi lbelajaratauprestasibelajardapatdipengaruhi oleh beberapafaktoryaitufaktor yang berasaldaridalamdirisiswa dan faktor yang berasaldariluardirisiswa.

Selainkeduafaktortersebutada juga faktorsistempembelajaran yang diterapkan di sekolah. 
JurnalSantiaji Pendidikan, Volume 10, Nomor2, Juli 2020 ISSN 2087-9016, e-ISSN 2685-4694

Faktor-faktor yang

mempengaruhibelajarbanyakjenisnya,

tetapidapatdigolongkanmenjadiduagolonga

nsajayaitu: (a) faktor intern,

meliputifaktorfisiologi dan psikologis.

Faktorfisiologissepertikeadaanjasmani dan

pancaindera.

Faktorpsikologis,

sepertiintelegensi, minat dan motivasi. (b)

faktorekstern, meliputifaktorsosial dan non sosial.

Faktorsosial, sepertilingkungankeluarga, sekolah dan masyarakat. Faktor non-sosial, sepertilingkunganalam dan fisikyaknikeadaanrumah, ruangbelajar, fasilitasbelajar, buku-bukusumber dan lain sebagainya(Mulyasa, 2005).

\section{METODE PENELITIAN}

Mutupendidikan

belummaksimalmenuntut

yang

guru-guru

untukmelakukanperbaikanprestasibelajarde

nganmelakukanpenelitiantindakankelas,

sehinggapenelitimelakukannya di SMP

Negeri

3

Banjarangkan.Sebuahpenelitiantidakbisaterl epasdarisebuahrancangan. Rancangan yang dibuatdalampenelitianinimengikutimodel

(Arikunto,

Suharsimi,

2007).

Berdasarrancangandiatasmakalangkah yang dilakukan:Denganmulaiadanyasuatupermas alahan. Setelah diketahuiadamasalah, dibuatperencanaan, kemudiandilaksanakan, diamati dan dilakukanrefleksi. Setelah refleksiakanterlihatpermasalahan yang tersisa yang merupakanmasalahbaru. Denganadanyamasalahbarumakadibuatpere ncanaanulang, dilaksanakan, diamati dan dilakukanrefleksi.

Bilapermasalahanbelumbisadiatasimakadila njutkandengansiklusberikutnya.

Penelitimenetapkansubjekpenelitian berdasarkanketentuanbahwasiswa pada kelasVII B SMP Negeri 3 BanjarangkanmasihbelummemenuhiKriteri
aKetuntasan Minimal yang ditetapkanuntukmatapelajaranIPA yang berjumlah

orang.Objekpenelitianmerupakan sebuah alternatif tindakan yang dimanfaatkan untuk menghasilkan perbaikan yang diinginkan. Dari tindakan tersebut peneliti mendapatkan data yang diinginkan. Karena itu objek penelitian perlu ditetapkan yaitu upayameningkatkanprestasibelajarsiswasete lahditerapkannya model pembelajaranproblem basedlearning dengan strategi snowballthrowing.Pelaksanaan proses pembelajaran yang berlangsung secara aktif pada awal semester menjadi tonggak dimulainya penelitian tindakan kelas pada semester ini. Awal aktifnya proses pembelajaran di sekolah pada semester ini dimulai dari bulan Juli 2018 sampai dengan Nopember2018.

Mendapatkan data tentang hasil belajar yang diperoleh siswa setelah pelaksanaan tindakan dilakukan guru dengan melakukan observasi melalui tes prestasi belajar. Analisis data dilakukan untuk mengetahui apakah terjadi peningkatan prestasi siswa secara signifikan atau tidak setelah dilakukan pengolahan data hasil penelitian. Untuk data kuantitatif dianalisis dengan mencari mean, median, modus, membuat interval kelas dan melakukan penyajian dalam bentuk tabel dan grafik.

\section{HASIL DAN PEMBAHASAN}

Dari 30siswa yang diteliti, ada 9 orang $(30 \%)$ yang memperoleh penilaian diatas KKM, 12 orang (40\%) yang memperoleh penilaian sama dengan KKM dan 9 orang (30\%) memperoleh nilai dibawah KKM artinya mereka baru mulai giat untuk belajar.Dari hasil tersebut gambaran yang dapat disimpulkan adalah 
JurnalSantiaji Pendidikan, Volume 10, Nomor2, Juli 2020 ISSN 2087-9016, e-ISSN 2685-4694

masih banyak anak yang belum mencapai penilaian sesuai harapan atau masih banyak anak yang belum mencapai keberhasilan seperti tuntutan indikator. Data dapat dilihat pada Tabel.1

Tabel1. Data Kelas IntervalSiklus I

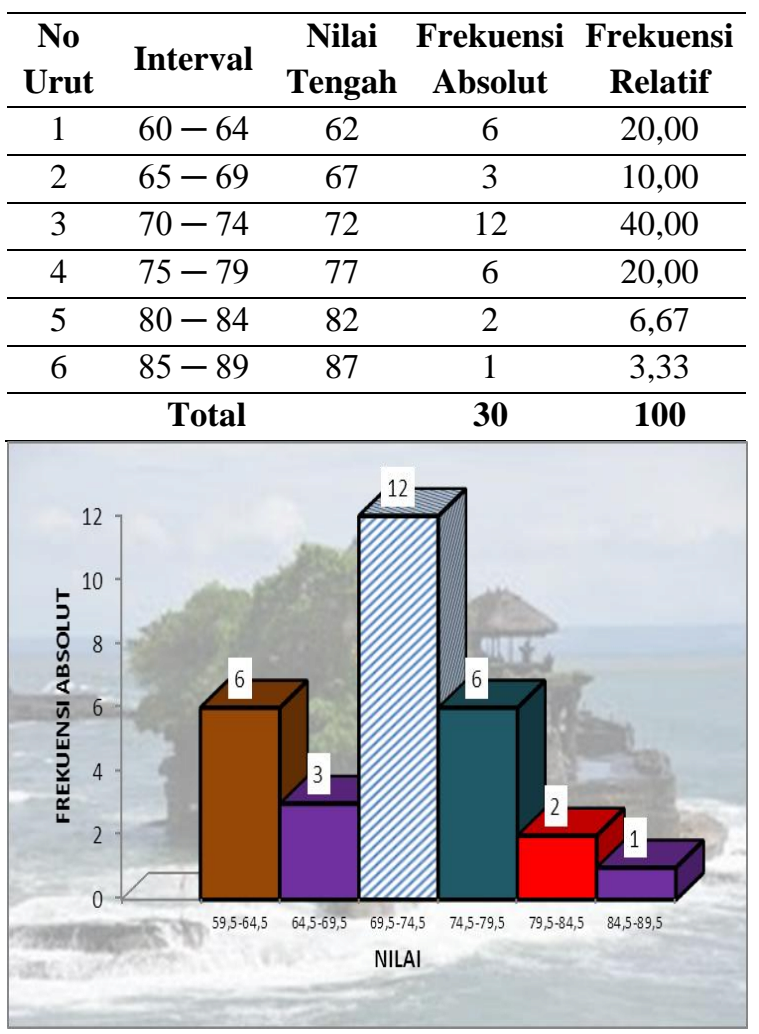

\section{Gambar 1. Histogram Siklus I}

Kekurangan-kekurangan yang adadaripelaksanaantindakansiklus I adalah: 1) Metode yang dipakaimengajarmasihlebihbanyakdidomin asi oleh ceramahsehingamateribelummaksimaldala mpenyerapannya.

Pendekatanpembelajaranbelummampumem buatsiswauntukaktifbelajar. 3) Guru belumsepenuhnyamenguasaiketerampilanketerampilanmengajar.

Kemauansiswauntukmenyelesaikantugastugas yang disuruhmasihrendah. Siswabelumaktifdalambertanya.

Kebiasaansiswa yang seringbermain-main membuatsiswakurangtermotivasiuntukgiatb elajar. 7) Siswatidaktertarik pada media pembelajaransehinggaperludibuat mediamedia yang menarik dan menyenangkan.

Sedangkankelebihan

yang ditemukan pada pelaksanaantindakansiklus I adalah: 1) Objektivitaspelaksanaan proses pembelajaran yang barumampuditunjukkandengan model ini, guru

mampuberpikirdeduktifinduktifdalammeme cahkansuatupermasalahan. 2) Guru mampumeningkatkanperannyasebagaifasilit ator, motivator, pengajar, pendidik, sertamampumengembangkanprofesionalis me dan mampumelaksanakanpembelajaran yang nyatanyatadapatmeningkatkanprestasibelajarsisw a.

Pada siklus II dari 30 peserta didik yang diteliti ada 28 orang $(93,33 \%)$ yang tingkat perkembangannya melebihi indikator yang dituntut. Yang lainnya ada 2 orang $(6,67 \%)$ yang berkembang sesuai harapan. Data ini menjelaskan ada $100 \%$ siswa yang tingkat perkembangannya mencapai hasil sesuai harapan. Deskripsi yang dapat disimpulkan adalah terjadinya peningkatan hasil dari siklus I 70\% pada siklus II ini menjadi $100 \%$. Hal tersebut berarti pembelajaran yang dilakukan guru sudah berhasil, bimbingan yang dilakukan sangat berhasil. Alat-alat yang digunakan sudah merupakan kesenangan peserta didik. Pengalihan perhatian peserta didik untuk giat ikut dalam pembelajaran sudah maksimal. Data kelas interval siklus II dapat dilihat pada Tabel 2.

Tabel2. Data Kelas IntervalSiklus II

\begin{tabular}{ccccc}
\hline $\begin{array}{c}\text { No } \\
\text { Urut }\end{array}$ & Interval & $\begin{array}{c}\text { Nilai } \\
\text { Tengah }\end{array}$ & $\begin{array}{c}\text { Frekuensi } \\
\text { Absolut }\end{array}$ & $\begin{array}{c}\text { Frekuensi } \\
\text { Relatif }\end{array}$ \\
\hline 1 & $70-74$ & 72 & 3 & 10,00 \\
\hline 2 & $75-79$ & 77 & 3 & 10,00 \\
\hline 3 & $80-84$ & 82 & 10 & 33,33 \\
\hline 4 & $85-89$ & 87 & 9 & 30,00 \\
\hline 5 & $90-94$ & 92 & 4 & 13,33 \\
\hline
\end{tabular}




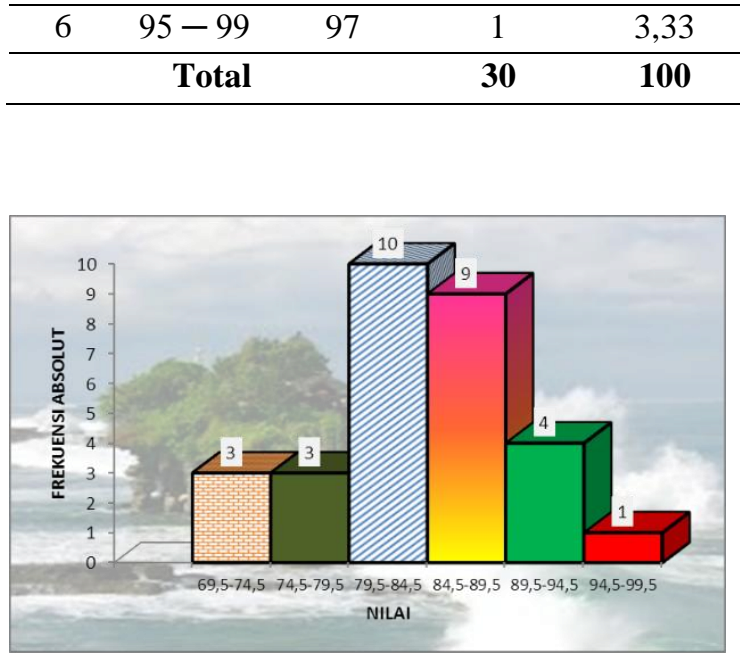

Gambar 2. Histogram Siklus II

Kelemahan-kelemahan yang adadaripelaksanaantindakansiklusII adalah: 1) Denganstrategi yang berbedasiswamasihmenungguperintah guru. 2) Kebiasaansiswa yang seringbermainmain

membuatsiswakurangtermotivasiuntukgiatb elajar

Sedangkankelebihan

yang ditemukan pada pelaksanaantindakansiklus IIadalah: 1) Model yang barumampumengasahkemampuanmerekada lamberdiskusi, bertukarpendapat. 2) Kecepatanpeningkatanprestasipesertadidikd alammenguasaimaterimampulebihdioptimal kan. 3) Model inimampumempertinggiminatsiswadalambe lajar, meningkatkansemangatmereka, meningkatkanantusiasmepesertadidik, sertamampumembuatpesertadidiklebihbers ungguh-sungguhdalammengerjakantugas dan dalambelajar. 4) Model ini juga mempunyaikelebihandalammeningkatkank esungguhansiswamengikuti proses belajarmengajar yang selalumenuntutkesiapansiswauntukmeneri maujian-ujiandari guru. 5) Model initernyatamempunyaikelebihanyaitumenun tut guru sebagaipenelitiuntukmenyiapkanperencana an yang lebihbaik

dan

mampumelaksanakan

proses

pembelajaranmengikutialur yang

ditetapkan. Jadi guru lebihsiap dan lebihgiatdalammenemukanteorisertatindaka $\mathrm{n}$ yang tepatsewaktumelaksanakan proses pembelajaran.

\section{SIMPULAN DAN SARAN}

Bertitik tolak dari perumusan masalah yang diajukan dalam Penelitian Tindakan Kelas ini dan berdasarkan data hasil penelitian serta analisisnya, maka dapat ditarik kesimpulan bahwa pembelajaran dengan memanfaatkan model pembelajaran problem based learning dengan strategi snowball throwing sangat efektif untuk meningkatkan prestasi belajar siswa pada mata pelajaran IPA di kelas VII B semester Itahun pelajaran 2018/2019 di SMP Negeri 3 Banjarangkan.

Keberhasilan tersebut terlihat dari adanya peningkatan hasil belajar yang diperoleh siswa dari data awal nilai rataratanya60,33dan tingkat ketuntasan belajar yang baru mencapai 30\%. Setelah diterapkan model pembelajaran problem based learning dengan strategi snowball throwing dalam proses pembelajaran maka pada siklus I diperoleh peningkatan prestasi belajar siswa dengan nilai rata-rata 69,87 tingkat ketuntasan belajar mencapai $70 \%$, dan pada siklus II diperoleh peningkatan prestasi belajar siswa dengan nilai ratarata82,10dan tingkat ketuntasan belajar mencapai $100 \%$.

Berdasarkan hasil penelitian, peneliti dapat memberikan beberapa saran sebagai berikut: 1) Kepada pihak Sekolah: Mengingatkan pentingnya inovasi dalam proses pembelajaran yangdigunakan dalam memperkaya metode-metode belajar yang sudah ada,maka disarankan agar kepala sekolah secara rutin mengadakan 
JurnalSantiaji Pendidikan, Volume 10, Nomor2, Juli 2020 ISSN 2087-9016, e-ISSN 2685-4694

pelatihanuntuk para guru. Melalui

pelatihan, ingatan guru akan kembali

disegarkanserta pengetahuan dan

keterampilan untuk mengaplikasikan

penerapanmodel pembelajaran problem

based learning dengan strategi snowball

throwingakan bertambah. 2) Kepada Guru

Pengampu Mata Pelajaran: Hendaknya dapat mengajarkan kepada anak didik denganmemperhatikan kondisi psikologis siswa apakah mereka siap untukmenerima pelajaran, serta adanya inovasi dalam metode pembelajarandikelas. Hal ini merupakan faktor yang sangat penting untukmengantisipasi agar siswa tidak jenuh dengan suasana belajar mengajar dikelas.

\section{DAFTAR PUSTAKA}

Barrows, H. S., \& Tamblyn, R. M. (1980). Problem-based learning: Rationale and definition. In Problem based-learning: An approach to medical education.

Hamalik, O. (2011). Doc 17. In Proses Belajar Mengajar.

Mulyasa, E. (2005). Menjadi guru profesional menciptakan pembelajaran kreatif dan menyenangkan. In Bandung: Remaja Rosdakarya.

Sudjana, N. (2009). Penilaian Hasil Proses Belajar Mengajar. In Sinarbaru.

Widodo, P. S. (2009). Meningkatkan Motivasi Siswa Bertanya melalui Metode Snowball-throwing dalam Pelajaran Pendidikan Kewarganegaraan. Jurnal Pendidikan Penabur. 